Research Article

\title{
Study on Permeability of Deep-Buried Sandstone under Triaxial Cyclic Loads
}

\author{
Mingqiang Sheng $\mathbb{D}^{1},{ }^{1}$ Awei Mabi, ${ }^{2}$ and Xigen Lu $\mathbb{D}^{2}$ \\ ${ }^{1}$ School of Civil Engineering and Architecture, Nanchang University, Nanchang 330031, China \\ ${ }^{2}$ School of Human Settlements and Civil Engineering, Nanchang Institute of Science and Technology, Nanchang 330108, China
}

Correspondence should be addressed to Xigen Lu; 1061807832@qq.com

Received 19 November 2020; Revised 17 December 2020; Accepted 4 January 2021; Published 25 January 2021

Academic Editor: Zhi Cheng Tang

Copyright (c) 2021 Mingqiang Sheng et al. This is an open access article distributed under the Creative Commons Attribution License, which permits unrestricted use, distribution, and reproduction in any medium, provided the original work is properly cited.

\begin{abstract}
The triaxial cyclic loading and unloading test was carried out on a TAW-2000 rock mechanics to study the permeability characteristics of deep-buried sandstone. This paper analyzed the evolution laws of permeability, elastic modulus, rock damage, dissipated energy, and acoustic emission events of sandstone under different confining pressures. It also introduced the concept of relative strain and further discussed the relationship between relative strain and permeability. The test results showed that the permeability of sandstone under cyclic loading and unloading obviously experienced three stages. At a low strain level, the damage degree of sandstone was low. As a result, both the number of acoustic emission events and the proportion of the dissipated energy density were small. In this stage, with increasing the stress, the permeability decreased. With the increase of the relative strain, the propagation of fissure increased through rock interior and the damage of rock was accumulated. Consequently, the number of acoustic emission events grew slowly, and the proportion of dissipated energy density and the damage variable $(D)$ increased gradually. In this stage, the permeability increases. As the axial strain reached the peak strain, the fissures developed into cracks and the rock failure happened. The number of acoustic emission events increased rapidly; both the proportion of the dissipated energy density and the damage variable $(D)$ obtain the maximum value. In this stage, the permeability increased greatly. In this study, the point of fissure propagation of rock specimens was used as the point of demarcation. Before the fissures propagated, the permeability increased slowly and it was in accordance with a linear function. After the fissures propagated, the degree of rock damage increased, and the permeability increased in the form of an exponential function. The larger the confining pressure was, the smaller the relative strain corresponding to the point of fissure propagation was.
\end{abstract}

\section{Introduction}

China is rich in coal resources with the characteristics of the various covered depth of the coal seams. Along with the exhausting shallow resources, the mining depth is increasing with an average rate of $8-25 \mathrm{~m}$ per year $[1,2]$. Deep mining has already become a trend in the coal industry. Under the high-stress condition, the mechanical characteristics of the coal and rock mass in the deep Earth are easily affected by underground engineering. With groundwater under high pressure, water inrush from rock formations is a serious potential risk during mining activities [3-8].

Deep mining causes the adjustment of the stress state of the coal and rock mass, which further leads to the change of their mechanical properties. The cyclic loading and unloading test is an effective method to understand the permeability evolution of the coal and rock mass under confining pressure. Many scholars have studied the hydraulic and mechanical properties of the coal and rock mass. For example, according to the seepage properties of sedimentary rocks in the stress-strain process, Peng et al. [9] summarized the relation curve between strain and permeability of rocks. With the permeability and mechanics characteristics test studying on sandstone and granite, Wang et al. [10] studied the evolution law of permeability with confining pressure, seepage pressure, and volumetric strain and established the relation between rock permeability and strain. Kong et al. [11] analyzed the relationship between 
permeability and porosity under cyclic loading, based on the experimental study on the gas permeability of sandstone under cyclic loading and unloading. Chen et al. [12] studied the permeability and nonlinear damage characteristics of rock under triaxial load based on RFPA software. Yang et al. [13] designed an experiment on the permeability evolution of coal and rock mass under cyclic seepage pressure and discovered the evolutionary characteristics of permeability of coal and rock mass and its relationship with seepage pressure. Generally speaking, previous studies mostly focused on the loading path of rock permeability and its mechanics characteristics.

Deformation and failure of coal and rock mass are damage processes, accompanied by the accumulation, evolution, and dissipation of energy. Peng et al. [14] analyzed the energy mechanism of the evolutionary process of damage of coal and rock mass under various confining pressures and concluded that the energy dissipation of damage increases with the increase of cyclic stress. Meng et al. [15] conducted experimental research on the energy evolution laws of sandstone with different loading rates under uniaxial cyclic loading and unloading. Li et al. [16] studied the energy evolutionary characteristics of granite under different loading and unloading paths and indicated that the ratio of dissipative energy can be used for describing the degree of rock deformation and failure. Li et al. [17] studied the permeability and acoustic emission characteristics of coal under different stress paths and found that the cumulative dissipated energy of coal increases exponentially with the axial effective stress. Cai et al. [18] studied the relationship between acoustic emission $b$-value characteristics and rock damage. Based on the study of the permeability evolution law of the damage of coal and rock mass, Zou et al. [19] obtained the relationship between damage characteristics and permeability of granite through the compression test. Zhao et al. [20] used acoustic emission (AE) to obtain the damage and permeability evolution characteristics of rock under stress. Wang et al. [21] conducted cyclic loading and unloading tests on deep coal and rock masses under confining pressure obtained the permeability of coal and rock mass and established its relationship with various mechanical properties of coal and rock mass.

Previous tests, in most cases, mainly focused on the shallow coal and rock mass under cyclic loading and unloading. There is a lack of analysis of permeability characteristics of coal and rock mass with multiparameters in the deep. The coal stratum in the deep coal mine is mainly sandstone. Therefore, taking into account the strong disturbance caused by mining activities, this paper will study the permeability of deep rocks under different confining pressures through the permeability test of cyclic loading and unloading.

\section{Characteristics of Specimens and Test Methods}

2.1. Sample Preparation. The testing object is the sandstone collected from 7302 working face of Baodian Coal Mine
(Shandong Province, China)) at a depth of $700 \mathrm{~m}$. The vertical bedding direction is densely drilled and sampled. Before selecting the specimens having similar wave speeds and having no large fissures by NM-4B sonic apparatus, all intact cylinder specimens were cored from the same block of sandstone material to a diameter of $50 \mathrm{~mm}$ and a length of $100 \mathrm{~mm}$, in accordance with the suggestion by ISRM. The main mineral compositions of the sandstone are quartz and clay minerals, including quartz (52\%), ankerite (10\%), clay minerals (31\%) such as illite and kaolinite, and with minor quantities of plagioclase and Siderite. Water was used as the infiltration medium, and the osmotic pressure difference was $3 \mathrm{MPa}$. Before the test, the rock sample was saturated with water through the vacuum immersion method.

2.2. Test Equipment and Method. TAW-2000 type testing machine, as shown in Figure 1, was used for the triaxial cyclic loading test. The test steps are as follows: (1) in the test process, the confining pressure was firstly loaded to the corresponding confining pressure state using a loading rate of $0.01 \mathrm{MPa} / \mathrm{s}$, and the confining pressures were selected as $5 \mathrm{MPa}, 10 \mathrm{MPa}$, and $15 \mathrm{MPa}$, respectively. The constant osmotic pressure was $3 \mathrm{MPa}$; (2) the axial pressure was controlled by displacement. The loading rate was $0.01 \mathrm{~mm} /$ $\mathrm{min}$, and the permeability was determined by loading to the initial predetermined value, which is $60 \%$ of the predicted peak strength; (3) unloading to hydrostatic pressure at a rate of $0.04 \mathrm{~mm} / \mathrm{min}$ to complete a cycle; (4) the upper limit stress level of each cycle is increased by $10 \%$ of the peak stress of triaxial compression under the same conditions of steps (2) and (3) until the specimen was destroyed. It should be noted that the peak compressive strength of sandstone under confining pressure of $5 \mathrm{MPa}, 10 \mathrm{MPa}$, and $15 \mathrm{MPa}$ were $85 \mathrm{MPa}, 150 \mathrm{MPa}$, and $215 \mathrm{MPa}$, respectively.

According to the traditional transient method, the permeability can be calculated by the following equation[19]:

$$
K=\mu \beta V \frac{\ln \left(\Delta P_{i} / \Delta P_{f}\right)}{2 \Delta t\left(A / L_{s}\right)},
$$

where $K$ is permeability $\left(\mathrm{m} \cdot \mathrm{s}^{-1}\right) ; \mu$ represents the viscosity of water $(0.001 \mathrm{~Pa} \mathrm{~s}) ; \beta$ represents compression coefficient of water $\left(4.53 \times 10^{-10} \mathrm{~Pa}^{-1}\right) ; V$ represents the volume of the hydraulic chamber $\left(\mathrm{m}^{3}\right) ; \Delta P_{i}$ and $\Delta P_{f}$ represent initial and final osmotic pressure difference $\left(P_{a}\right)$, respectively; $\Delta t$ is the duration of measuring permeability; $A$ and $L_{\mathrm{s}}$ represent the cross-sectional area $\left(\mathrm{m}^{2}\right)$ and height $(\mathrm{m})$ of the sample.

The acoustic emissions signals were captured and collected synchronously during the triaxial test process. After the acoustic emission sensor was coated with petrolatum, the pressure was given by the clamping ring to make it closely contacted with the outer wall of the triaxial chamber. The threshold value of acoustic emission was set to $35 \mathrm{~dB}$.

\section{Results and Analysis}

3.1. Permeability and Stress-Strain. The mechanical characteristics of the rock specimens under triaxial compression are shown in Figure 2. As we can see from Figure 2, there 


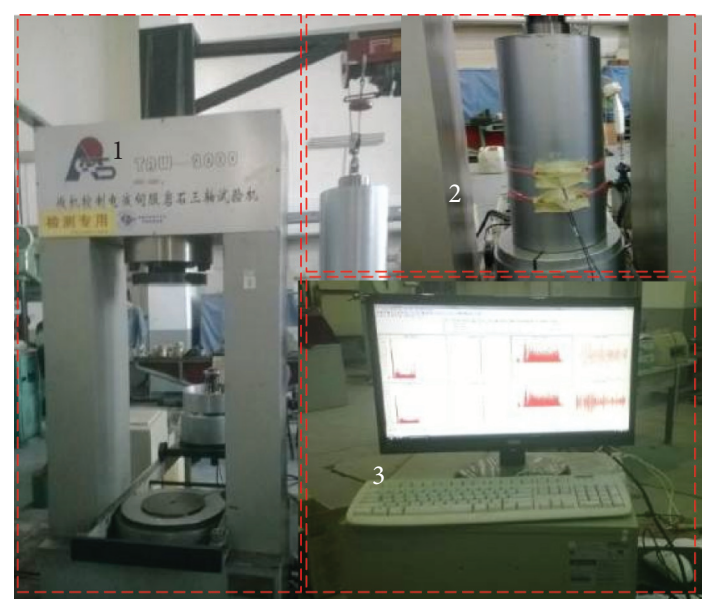

FIgURE 1: TAW-2000 rock mechanics testing system.

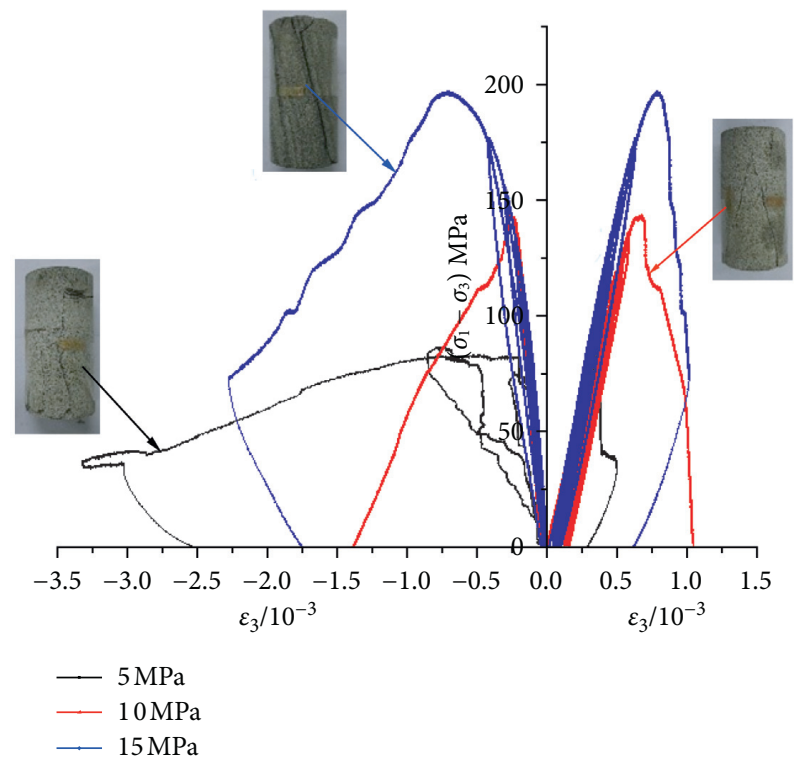

FIGURE 2: Stress-strain curves of rock samples under different confining pressures.

were 4 stages including the initial compression, elastic deformation, plastic yield, and to the post-peak failure state, during the triaxial compression process. A positive correlation can be found between the confining pressure and the peak strength as well as the peak strain. The loading curve deviated from the original loading curve after the specimen was unloaded to zero and then loaded again. During the compaction process, the axial deformation of the rock was slow. After the peak stress occurred and the rock underwent the failure stage and the axial strains increased sharply and obviously. This phenomenon indicates that the deep rocks have characteristics of brittleness which makes the rocks still have residual strength in some degree even after failure.

In order to study the deformation characteristics of the sandstone under cyclic loading and unloading, the evolution of the elastic modulus of the specimen has been recorded. This paper uses the unloading secant modulus to characterize the elastic modulus. Figure 3 shows the rock under

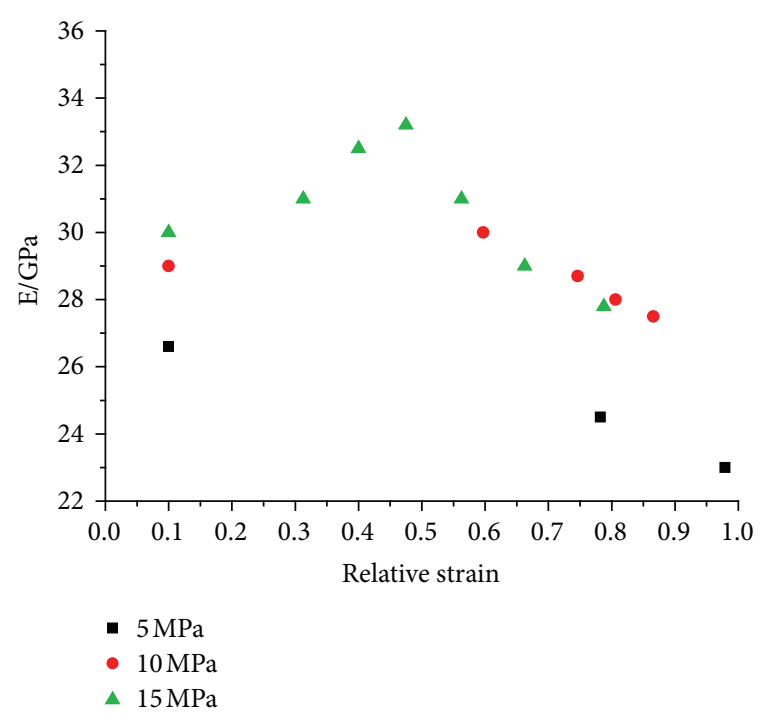

FIgURE 3: Evolution of elastic modulus under different confining pressures.

loading and unloading displays compaction before it enters the yield failure, and with the increase of stress, the elastic modulus of the rock increases first and then decreases. Meanwhile, the elastic modulus is positively associated with confining pressure.

The elastic modulus of the rock continuously changes with stress and strain. The damage variable can be written as follows and can be used to describe the damage degree of the rock under loading and unloading [22].

$$
\begin{aligned}
& D=1-\frac{E_{i}}{E_{0}}, \\
& \varepsilon_{\eta}=\frac{\varepsilon_{i}}{\varepsilon_{t}},
\end{aligned}
$$

where $D$ is the damage variable; $E_{i}$ is the unloading rigidity; $E_{0}$ is the initial elastic modulus of the rock, which is also known as the undamaged modulus. $\varepsilon_{n}$ is the relative strain, the dimensionless parameters; $\varepsilon_{i}$ and $\varepsilon_{t}$ are unloading strain and peak strain, respectively. The positive and negative values of $D$ indicate fracture damage and density damage, respectively.

Figure 4 demonstrates the damage variable $(D)$ and the evolution law of the permeability. The horizontal axis represents the relative strain, the ratio of corresponding strain to peak strain. The test indicates that with the increase of the relative strain, the permeability of sandstone decreases first and then increases, and there is a correlation between the permeability and damage variable $(D)$. Before the rock deformation gets in the plastic zone, the rock is in the compaction stage (a negative value of $D$ ), and the permeability decreases. In contrast, after the rock deformation goes into the plastic zone, the rock gets in the stage of expansion (a positive value of $D$ ), and the permeability increases. When the peak pressure is interrupted, the fissures of the specimen are expanded and the permeability increases rapidly. The permeability at the state of hydrostatic pressure under 


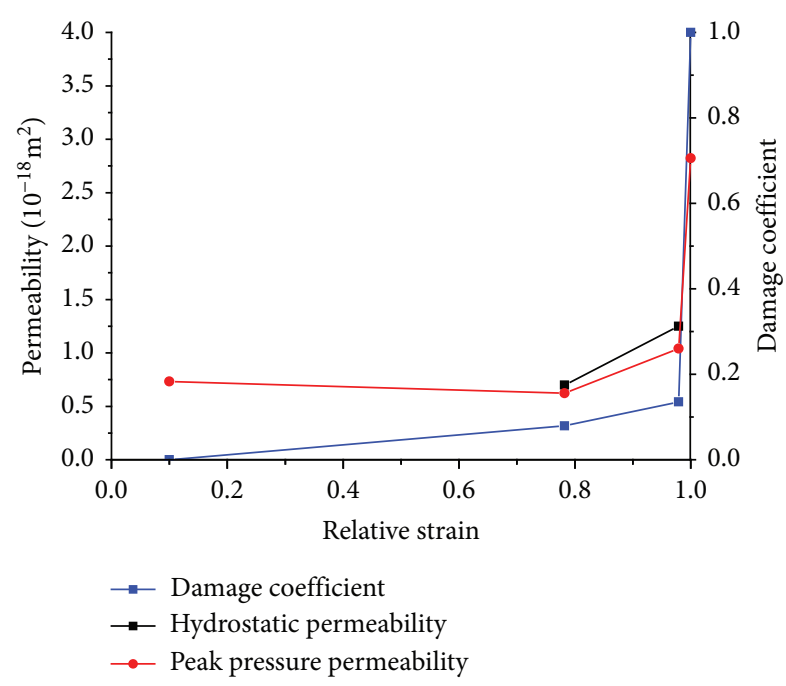

(a)

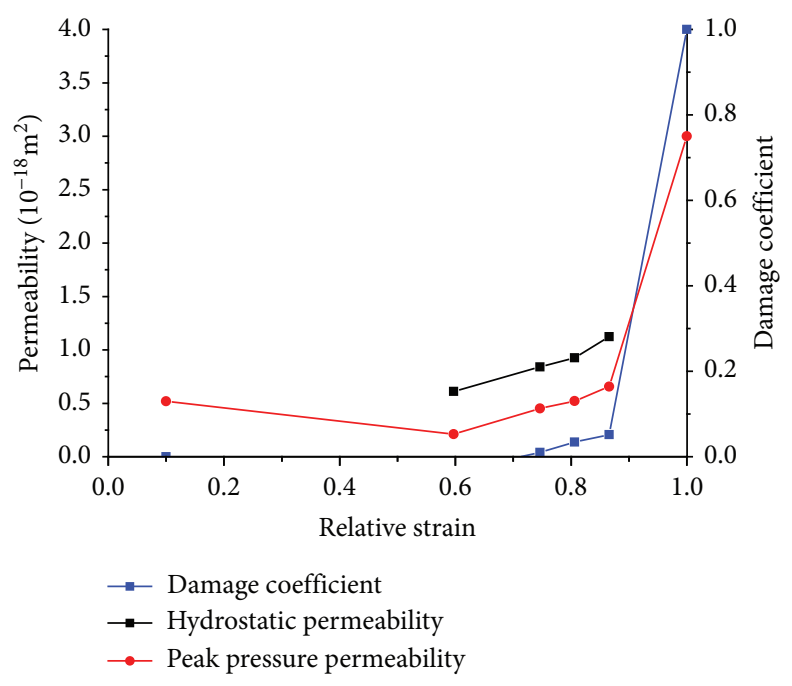

(b)

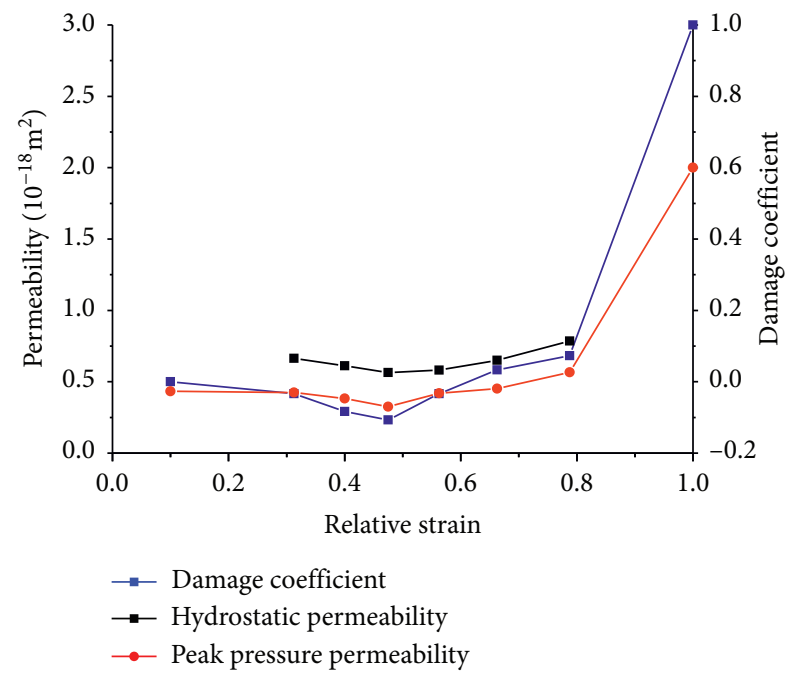

(c)

Figure 4: Evolution of permeability with damage D under different confining pressure. (a) Confining pressures $5 \mathrm{MPa}$. (b) Confining pressures $10 \mathrm{MPa}$. (c) Confining pressures $15 \mathrm{MPa}$.

unloading is always higher than the permeability at the state of peak stress. According to the relationship between the damage variable $(D)$ and permeability and relative strain, the permeability of rocks under low confining pressure increases at a strain level of about 0.8 , and the permeability of rocks under high confining pressure changes at a strain level of 0.45 , indicating that the increase in confining pressure will reduce the strain level of rocks to get in the yield stage.

3.2. Permeability and Energy Characteristics. When the rock specimen is loaded under triaxial cyclic loads, the test system transfers mechanical energy to the specimen, a proportion of which is converted into elastic energy that is stored in the specimen and can be released entirely under unloading. The rest of the energy is consumed when the plastic deformation and the damage occur in the rock specimen, and it is irreversible. As the energy is consumed in the cyclic loading test and the dissipated energy of the rock specimen is irreversible, the hysteretic loop can be seen from the stressstrain curve [23]. The area under the unloading stress-strain curve is the elastic energy density $\left(U^{e}\right)$, and the area of the hysteresis loop in the loading-unloading stress-strain curve is the dissipated energy density $\left(U^{d}\right)$.

$$
\left\{\begin{array}{l}
U^{e}=\int_{\varepsilon^{\prime \prime}}^{\varepsilon^{\prime}} \sigma_{1} d \varepsilon_{1}, \\
U^{d}=\int_{0}^{\varepsilon^{\prime}} \sigma_{1} d \varepsilon_{1}-\int_{\varepsilon^{\prime \prime}}^{\varepsilon^{\prime}} \sigma_{1} d \varepsilon_{1},
\end{array}\right.
$$

where $\varepsilon^{\prime}$ and $\varepsilon^{\prime \prime}$ are the initial strain under unloading and the strain of hydrostatic pressure after unloading, respectively.

Based on the energy statistics resulted from different confining pressures given by the cyclic loading and unloading test, with the increase of the relative strain, the elastic energy and dissipated energy of the rock specimen 
increase before the peak value appears. Meanwhile, at the plastic yield stage, the dissipated energy continuously increases to the failure point where the peak value appears, and after the rock failure happens, the elastic energy decreases rapidly to a certain level which is considered as the residual elastic energy. With the increase of the confining pressure, the elastic strain energy of the specimen increases gradually and the peak elastic energy, maximum storage energy, and residual elastic energy all increase somewhat. However, the dissipated energy does not increase significantly before the rock failure happens.

The dissipated energy of rock often reflects its damage evolution, and the degree of the dissipated energy density is related to the internal damage of rock. Using the dimensionless parameter $\left(k_{d}\right)$, the proportion of dissipated energy can be written as follows:

$$
k_{d}=\frac{U^{d}}{\left(U^{e}+U^{d}\right)} .
$$

Figure 5 shows the relationship between the change in the proportion of dissipated energy density and the change in the permeability of the specimen under cyclic loading and unloading. From it, we can see (1) before the deformation of the specimen goes into the yield stage, the relative strain is low, the elastic characteristics are good, the dissipated energy density is low, and with the increase of strain, the permeability decreases. (2) when the strain goes into the field stage, the proportion of dissipated energy density grows gradually, the damage happens through rock interior, the main role of stress at this stage is a fracture, and with the increase of stress, the permeability increases slightly. (3) when the specimen reaches the peak value, the proportion of the dissipated energy density obtains the maximum value and the permeability achieves the highest level. There is a good correlation between permeability and the proportion of dissipated energy, indicating that, in the cyclic loading and unloading test, the proportion of dissipated energy can be used to predict the trend of change in permeability.

\subsection{Permeability and Acoustic Emission Characteristics.} Acoustic emission is a phenomenon caused by partial fracture of rock material and rapid release of energy in the form of elastic waves. The signal that the acoustic emission monitor captures and collects is the acoustic emission of rocks [24]. The generation of acoustic emission is related to the internal damage of the rock, and the cumulative acoustic emission events reflect the accumulated damages of the specimen under loading and unloading. Therefore, acoustic emission is important in evaluating the damage development in rocks under loading, and acoustic emission signals are monitored and used to associate different stages of crack development with different stages of the mechanical parameter evolution. Comparative analysis of acoustic emission characteristics and permeability of the specimens can indicate the evolutionary relationship between acoustic emission and permeability. Figure 6 demonstrates the evolution law of the permeability with the cumulative $\mathrm{AE}$ events.

As can be seen from Figure 6,

(1) With the characteristics of high strength and strong brittleness, at the low strain level, the degree of damage of sandstone under cyclic loading and unloading is low, the number of acoustic emission events is small, and with the increase of stress, the permeability decreases.

(2) As the strain is close to the yield stage, the number of acoustic emission events increases rapidly under loading, and the acoustic emission signal is less under unloading, indicating that at the yield stage, the plastic zone expands under loading and the damage of rock is closure under unloading. When the strain approaches the peak strain, the rock failure happens; the number of acoustic emission events has the highest increase amplitude, and relatively, the permeability increases rapidly.

\section{Discussion}

Based on the experimental data from the cyclic loading and unloading test on sandstone under different confining pressures, this paper analyzed the evolutionary relationship between permeability and relative strain, damage, energy density characteristics, and acoustic emission characteristics. The research reveals that the evolution law of permeability of the specimens under cyclic loads is roughly the same. Under cyclic loading and unloading, the damage degree of rock affects the permeability. In addition, damage coefficient, energy density characteristics, and acoustic emission characteristics can effectively describe the evolution of permeability with rock damage. Moreover, with the increases in the proportion of dissipated energy density, damage variable $(D)$, and the number of acoustic emission events, the permeability increases correspondingly. A case study from the specimen under a confining pressure of $15 \mathrm{MPa}$ can summarize the evolution law of permeability, as shown in Figure 7.

(1) The First Stage. The sandstone specimens go into the elastic compaction stage, the relative strain is low, the degree of rock damage is low, the number of acoustic emission events is small, the proportion of dissipated energy density is small, and with the increase of stress, the permeability decreases.

(2) The Second Stage. The sandstone specimens get into the stage of fissure propagation, the relative strain increases, the propagation of fissure increases through rock interior, the damage of rock is accumulated, the number of acoustic emission events grows slowly, the proportion of dissipated energy 


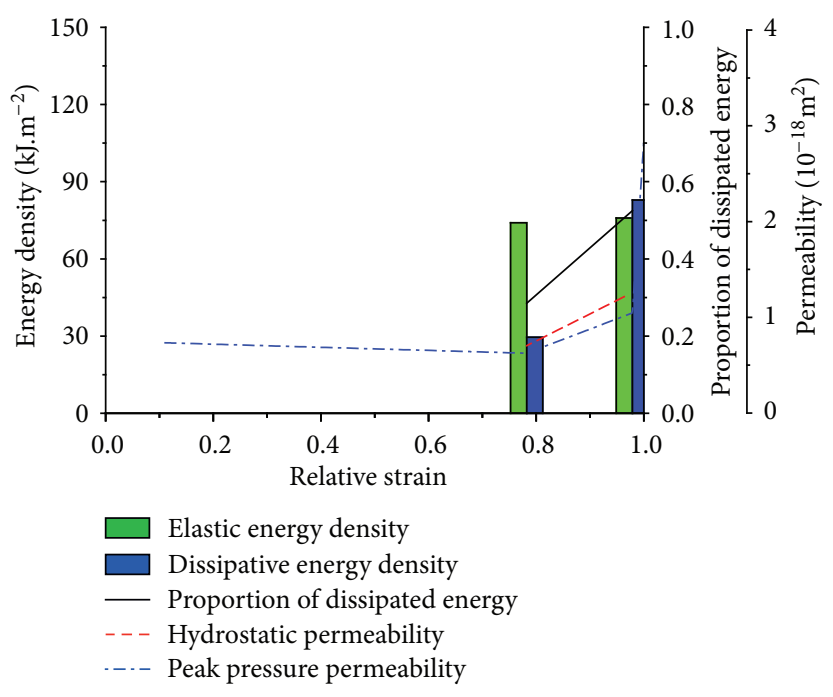

(a)

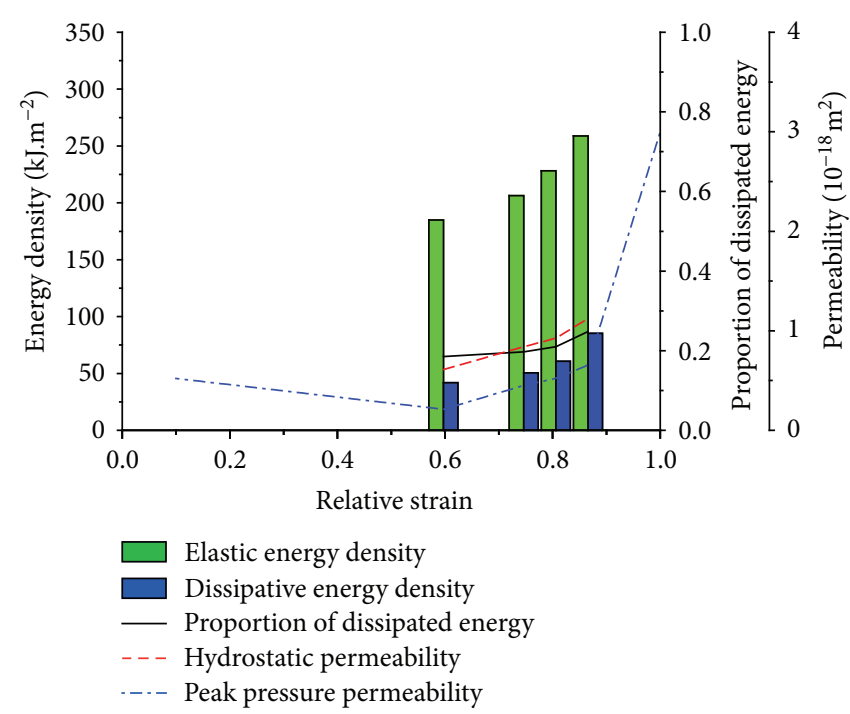

(b)

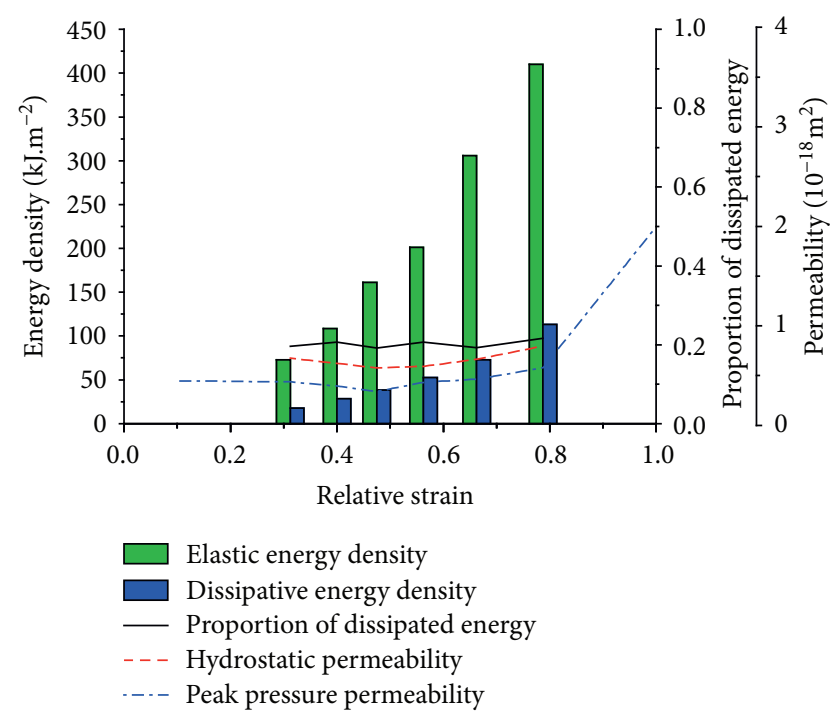

(c)

FIGURE 5: Evolution of permeability with energy under different confining pressures. (a) Confining pressures $5 \mathrm{MPa}$. (b) Confining pressures $10 \mathrm{MPa}$. (c) Confining pressures $15 \mathrm{MPa}$.

density, as well as damage variable $(D)$ increase gradually, and with the increase of the relative strain, the permeability increases.

(3) The Third Stage. The specimens go into the stage of yield failure, the axial strain reaches the peak strain, the fissures develop into cracks, the rock failure happens, the number of acoustic emission events increases rapidly, the proportion of the dissipated energy density, as well as damage variable $(D)$ obtain the maximum value, and the permeability increases greatly.

To sum up, during the compaction stage, the fissures do not propagate and the evolution trend of permeability decreases insignificantly; during the stage of fissure propagation, the permeability increases slowly and steadily; during the stage of yield failure, after the fissures develop into cracks and even cause macroscopic failure, the permeability increases significantly. There is a certain difference in relative strains which is related to different stages under different confining pressures. The permeability of rocks under low confining pressure increases at a strain level of about 0.8 , and the permeability of rocks under high confining pressure changes at a strain level of 0.45 , indicating that the increase in confining pressure will reduce the strain level of rocks to get in the yield stage.

Based on the analysis mentioned above, the permeability $(P)$ is closely related to the relative strain. The relationship 


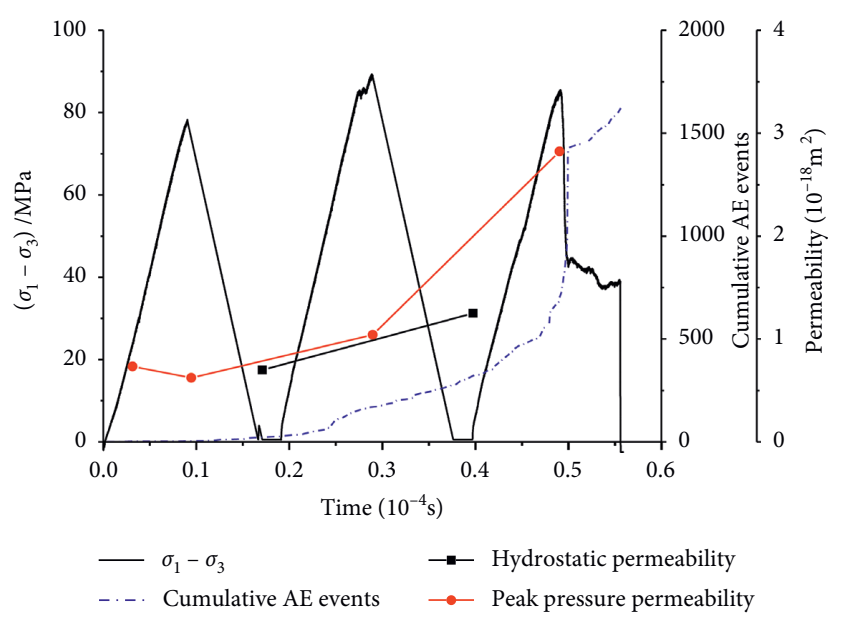

(a)

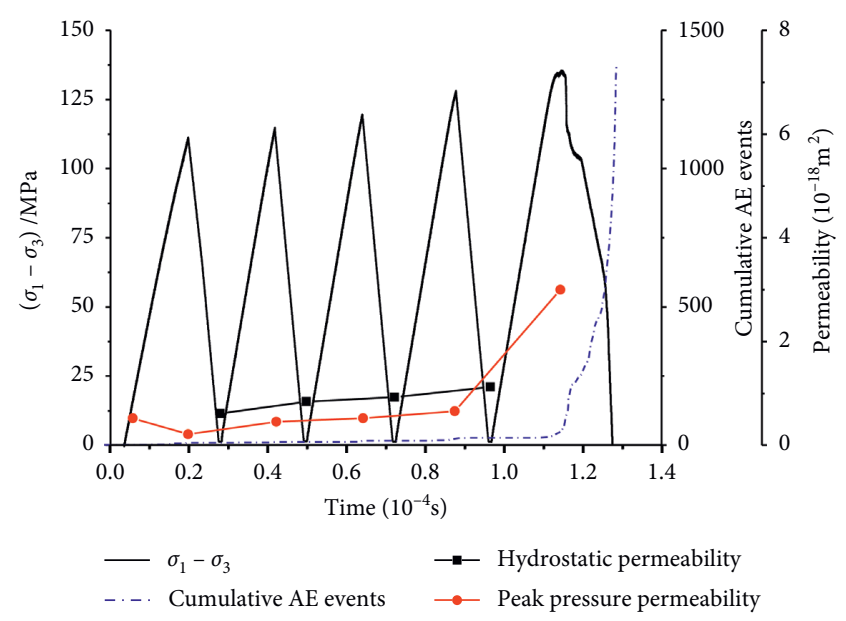

(b)

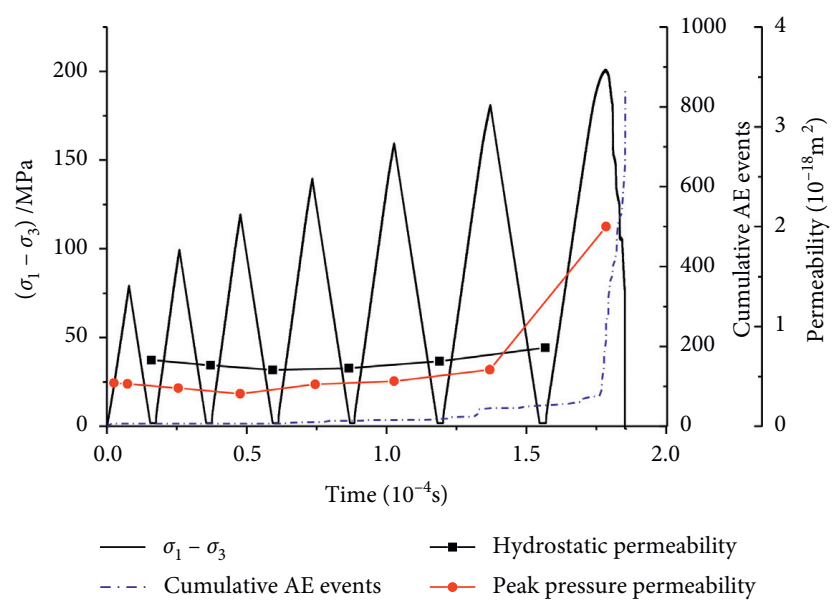

(c)

Figure 6: Permeability-accumulative AE events-time curves. (a) Confining pressures $5 \mathrm{MPa}$. (b) Confining pressures $10 \mathrm{MPa}$. (c) Confining pressures $15 \mathrm{MPa}$.

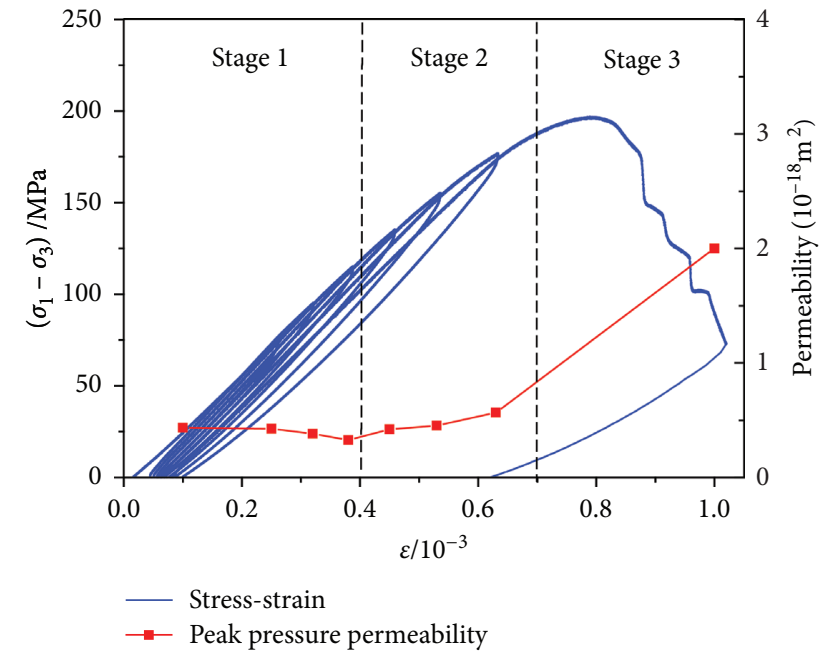

FiguRe 7: Evolution law of permeability. between permeability and the relative strain under a certain confining pressure can be written as follows [25]:

$$
P=\left\{\begin{array}{l}
a+b \varepsilon_{\eta}, \quad\left(\varepsilon_{\eta} \leq \varepsilon_{k}\right), \\
m e^{n\left(\varepsilon_{\eta}-c\right)}, \quad\left(\varepsilon_{\eta}>\varepsilon_{k}\right),
\end{array}\right.
$$

where $a, b, \mathrm{~m}$, and $p$ are fitting parameters; $n$ is the evolution rate of permeability; $\varepsilon_{k}$ is the relative strain of rock specimen at the stage of fissure propagation.

In this paper, the point of fissure propagation of rock specimens is used as the point of demarcation, and the permeability and relative strain are fitted in sections. The linear function is adopted before the fissures are propagated, and the exponential function is applied after the fissures are propagated. The fitting curve is shown in Figure 8. All the fitting correlation coefficients are relatively high. Therefore, the composite function shown in equation (5) can be used to simply describe the evolution law of permeability of the rock specimens at the stress-strain stage. Before the fissures propagated, the permeability decreases with the lowest rate 


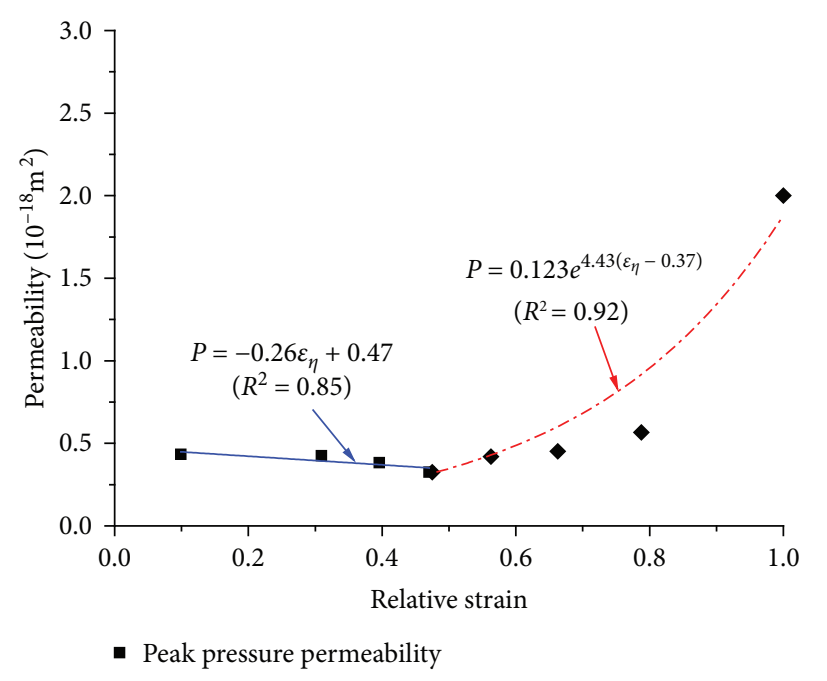

FIGURE 8: Fitting results of permeability and relative strain.

of evolution; however, after the rock specimens go into the yield stage, the permeability increases with the highest rate of evolution.

\section{Conclusions}

(1) In the process of cyclic loading and unloading, the mechanical damage state of rock affects permeability. The damage coefficient, energy density characteristics, and acoustic emission characteristics can effectively characterize the evolution characteristics of damage and permeability. The proportion of dissipated energy density and damage $D$ increase step by step, and the number of acoustic emission events increases, so does the permeability.

(2) In the process of rock cyclic loading and unloading, the permeability shows three obvious stages: low relative strain level stage, permeability decreases with the increase of stress, the relative strain level increases, the internal fracture of rock sample expands, the permeability increases with the increase of relative strain level, the axial strain reaches the peak strain, the fracture expands into the crack, and the permeability increases greatly.

(3) Taking the crack growth point of the rock sample as the boundary point, the permeability decreases slowly in the form of linear function before crack propagation and increases in the form of exponential function after fracture propagation; the greater the confining pressure is, the smaller the relative strain level corresponding to the fracture growth point is.

\section{Data Availability}

The data used to support the findings of this study can be obtained from the corresponding author upon request.

\section{Conflicts of Interest}

The authors declare that they have no conflicts of interest regarding the publication of this paper.

\section{Acknowledgments}

The authors gratefully acknowledge the financial support of the National Natural Science Foundation of China (52069013).

\section{References}

[1] H. P. Xie, J. H. Wang, B. H. Shen, J. Z. Liu, and G. Wu, "New idea of coal mining: scientific mining and sustainable mining capacity," Journal of China Coal Society, vol. 37, no. 7, pp. 1069-1079, 2012.

[2] L. Yuan, "Scientific conception of precision coal mining," Journal of China Coal Society, vol. 17, no. 42, pp. 1-7, 2017.

[3] Z. C. Tang and Y. Y. Jiao, "Choosing appropriate appraisal to describe peak spatial features of rock joint profiles," International Journal of Geomechanics, vol. 20, no. 4, Article ID 04020021, 2020.

[4] L. Wei, Q. Yue-ping, Z. Miao-miao, W. Cui-xia, and W. Yaru, "Test study on permeability properties of the sandstone specimen under triaxial stress condition," Procedia Engineering, vol. 26, pp. 173-178, 2011.

[5] J. P. Zou, Y. Y. Jiao, Z. C. Tang, Y. L. Ji, C. Z. Yan, and J. C. Wang, "Effect of mechanical heterogeneity on hydraulic fracture propagation in unconventional gas reservoirs," Computers and Geotechnics, vol. 125, Article ID 103652, 2020.

[6] Z. C. Tang, Q. Z. Zhang, and J. Peng, "Effect of thermal treatment on the basic friction angle of rock joint," Rock Mechanics and Rock Engineering, vol. 53, no. 4, pp. 1973-1990, 2020.

[7] L. Chen, J. F. Liu, C. P. Wang, J. Liu, R. Su, and J. Wang, "Characterization of damage evolution in granite under compressive stress condition and its effect on permeability," International Journal of Rock Mechanics and Mining Sciences, vol. 71, pp. 340-349, 2017.

[8] U. M. Yasidu, Y. Fujii, J.-i. Kodama et al., "Influences of water vapor on roof fall accidents in selected underground coal mines in Malawi," Advances in Civil Engineering, vol. 2019, pp. 1-17, Article ID 6243609, 2019.

[9] S. P. Peng, H. L Qu, L. P. Luo, L. Wang, and Y. E. Duan, “An experimental study on the penetrability of sedimentary rock during the complete stress-strain path," Journal of China Coal Society, vol. 25, no. 2, pp. 113-116, 2000.

[10] H. L. Wang, W. Y. Xu, and S. Q. Yang, "Experimental investigation on permeability evolution law during course of deformation and failure of rock specimen," Rock and Soil Mechanics, vol. 27, no. 10, pp. 1703-1708, 2006.

[11] Q. Kong, H. L. Wang, S. P. Ran, and Z. N. Lin, "Experimental investigation on relationship between porosity and permeability of sandstone under cyclic loading condition," Journal of China Three Gorges University (Natural Sciences), vol. 37, no. 4, pp. 55-61, 2015.

[12] X. Chen, J. Yu, C. A. Tang, H. Li, and S. Y. Wang, "Experimental and numerical investigation of permeability evolution with damage of sandstone under triaxial compression," Rock Mechanics and Rock Engineering, vol. 50, pp. 1529-1549, 2015.

[13] D. S. Yang, X. Y. Qi, W. Z. Chen, S. G. Wang, and J. P. Yang, "Anisotropic permeability of coal subjected to cyclic loading and unloading," International Journal of Geomechanics, vol. 18, no. 8, pp. 85-93, 2018.

[14] R. D. Peng, Y. Ju, F. Gao, H. P. Xie, and P. Wang, "Energy analysis on damage of coal under cyclical triaxial loading and unloading conditions," Journal of China Coal Society, vol. 39, no. 2, pp. 245-252, 2014. 
[15] Q. Meng, M. Zhang, L. Han, H. Pu, and T. Nie, "Effects of acoustic emission and energy evolution of rock specimens under the uniaxial cyclic loading and unloading compression," Rock Mechanics and Rock Engineering, vol. 49, no. 10, pp. 3873-3886, 2016.

[16] D. Li, Z. Sun, T. Xie, X. Li, and P. G. Ranjith, "Energy evolution characteristics of hard rock during triaxial failure with different loading and unloading paths," Engineering Geology, vol. 228, pp. 270-281, 2017.

[17] Q. Li, Y. Liang, Q. Zou, and Q. Li, "Acoustic emission and energy dissipation characteristics of gas-bearing coal samples under different cyclic loading paths," Natural Resources Research, vol. 29, no. 2, pp. 1397-1412, 2020.

[18] Y. Cai, D. Liu, J. P. Mathews et al., "Permeability evolution in fractured coal - combining triaxial confinement with X-ray computed tomography, acoustic emission and ultrasonic techniques," International Journal of Coal Geology, vol. 122, pp. 91-104, 2014.

[19] H. Zou, J. F. Liu, B. Yu, Z. W. Zhou, and Z. Yue, "Experimental study on mechanical and permeability properties of sandstone with different granularities," Chinese Journal of Geotechnical Engineering, vol. 37, no. 8, pp. 1462-1468, 2015.

[20] Y. Zhao, H. Zhou, J. Zhong, and D. Liu, "Study on the relation between damage and permeability of sandstone at depth under cyclic loading," International Journal of Coal Science \& Technology, vol. 6, no. 4, pp. 479-492, 2019.

[21] X. Y. Wang, H. W. Zhou, J. Zhong et al., "Study on energy evolution and permeability characteristics of deep coal damage under triaxial cyclic loading and unloading conditions," Chinese Journal of Rock Mechanics and Engineering, vol. 37, no. 12, pp. 2676-2684, 2018.

[22] J. W. Zhou, X. G. Yang, W. X. Fu et al., "Experimental test and fracture damage mechanical characteristics of brittle rock under uniaxial cyclic loading and unloading conditions," Chinese Journal of Rock Mechanics and Engineering, vol. 29, no. 6, pp. 1172-1183, 2015.

[23] H. P. Xie, Damage Mechanics of Rocks and Concrete, pp. 11-25, China University of Mining and Technology Press, Xuzhou, 1998.

[24] H. Li and H. Li, "Mechanical properties and acoustic emission characteristics of thick hard roof sandstone in Shendong coal field," International Journal of Coal Science \& Technology, vol. 4, no. 2, pp. 147-158, 2017.

[25] L. Chen, J. F. Liu, C. P. Wang, J. Liu, R. Su, and J. Wang, "Investigation on damage evolution characteristic of granite under compressive stress condition and its impact on permeability," Chinese Journal of Rock Mechanics and Engineering, vol. 33, no. 2, pp. 287-295, 2014. 